\title{
Fistula from coronary arteries to left ventricle after myocardial infarction ${ }^{1}$
}

\author{
COLMAN RYAN AND EDWARD W. GERTZ \\ From the Departments of Medicine and Surgery, School of Medicine, University of California, San \\ Francisco, and the Veterans Administration Hospital, San Francisco, U.S.A.
}

Coronary arteriography and left ventriculography, performed in a 42-year-old patient with unstable angina seven months after a myocardial infarct showed communications from both the left anterior descending and right coronary arteries to the left ventricular chamber. The area of communication corresponded to the site of infarction as established by electrocardiogram and left ventriculogram. Whether this is a congenital or acquired lesion is unclear.

Although there are many reports of congenital fistulae of the coronary arteries, congenital fistula to the left side of the heart appears to be a rare phenomenon (Hallman et al., 1966; McNamara and Gross, 1969; de Nef et al., 1971; Ogden and Stansel, 1972). We report here a patient who had a fistula, possibly acquired, from both left anterior descending and distal posterior descending coronary arteries to the left ventricle through the site of an old myocardial infarction.

\section{Case history}

The patient, a 42-year-old black man, was referred for investigation of exertional chest pain of 22 years' duration. He had noticed the gradual onset of mild chest pain with severe exertion; investigation at that time showed him to be a mild diabetic. An electrocardiogram was reported as within normal limits.

In July 1972 he was admitted to hospital for 2 months because of a prolonged episode of intermittent chest pain at rest associated with $T$-wave changes on the electrocardiogram. An exercise test in August 1973 showed $4 \mathrm{~mm}$ of junctional upsloping ST depression at one minute of stage II of the Bruce graded treadmill test (heart rate of 145 per minute). Three days later, he suffered an acute myocardial infarct of the inferior wall with classic 'Supported in part by grants from the University of California San Francisco Academic Senate Committee on Research (Barclay Endowment and Ethel Fine Endowment), and by the Medical Research Service of the Veterans Administration. evolution of electrocardiographic findings and serum enzymes. Complete heart block, requiring a temporary pacemaker, occurred on admission to the coronary care unit.

The patient's chest pain continued after discharge, and in November 1973 he began to have nocturnal angina and symptoms of mild paroxysmal nocturnal dyspnoea.

Physical examination revealed a moderately obese man with blood pressure of $125 / 80 \mathrm{mmHg}$. He was taking frusemide, $40 \mathrm{mg}$ daily, and spironolactone $100 \mathrm{mg}$ daily. There was no evidence of congestive heart failure. A loud $S_{4}$ sound was present but no murmurs were heard. Peripheral pulses were absent bilaterally distal to the popliteal pulses. His electrocardiogram showed signs of old inferior myocardial infarction with a PR interval of $0.18 \mathrm{~s}$ (Fig. 1). Chest $x$-ray examination showed a cardiac silhouette at the upper limits of normal size and no evidence of congestive heart failure. Risk factors included smoking, previous hypertension, diabetes, obesity, type IV hyperlipidaemia, and a strong family history of early death from coronary artery disease.

Cardiac catheterisation was performed in March 1974. Left ventriculography revealed an area of decreased motion of the inferior wall corresponding to the old infarction. Ejection fraction was 36 per cent. The left ventricular end-diastolic pressure was $6 \mathrm{mmHg}$ after angiocardiography. The right coronary artery was completely occluded distally, with reconstitution by collaterals from the marginal 


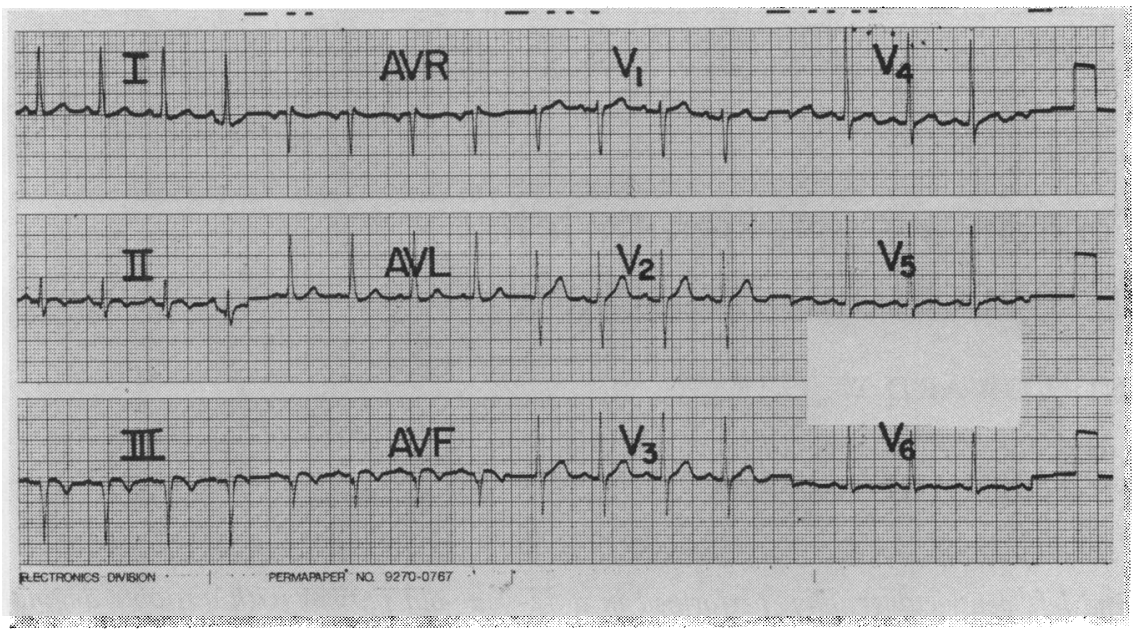

Fig. 1 Electrocardiogram before coronary angiography in March 1974. Old myocardial infarction of the inferior wall is evident.
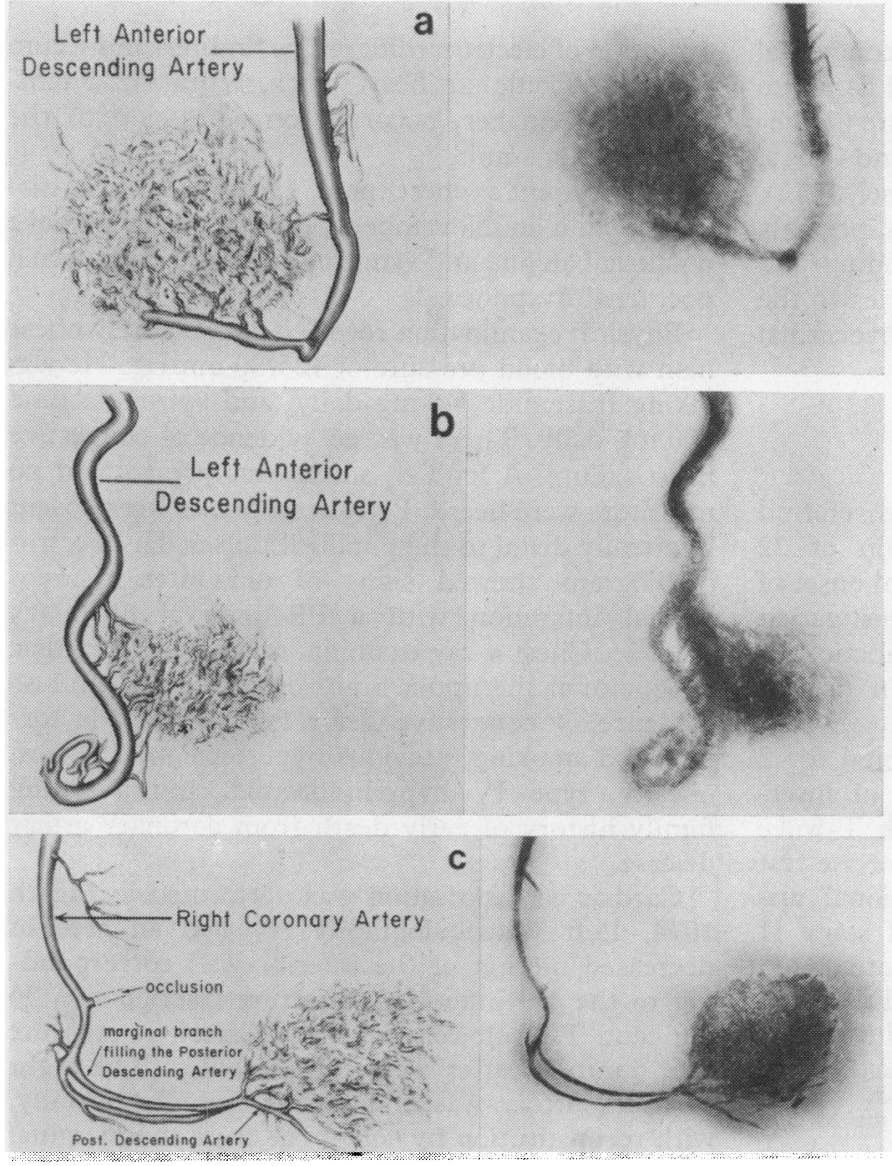

Fig. 2 Selective coronary angiography. (a) Distal left anterior descending coronary artery in the $30^{\circ}$ right anterior oblique position showing arteriosystemic communication. (b) Distal left anterior descending artery in the $30^{\circ}$ left anterior oblique position showing tortuosity of the vessel proximal to the communication. (c) Right coronary artery in the $30^{\circ}$ right anterior oblique position showing opacification of the arteriosystemic communication. 
branch. There were diffuse minor irregularities of the proximal right and posterior descending arteries. At the distal end of the latter, there was a localised triangular blush, with rapid passage of dye into the left ventricular chamber.

Injection of the left coronary artery showed no lesion in the main stem; the dilated, tortuous left anterior descending artery emptied very rapidly into a localised diffuse network of vessels which, in turn, emptied into the left ventricle (Fig. 2a and b). A portion of the fistula seen after injection of the left coronary artery was the same as that seen from the right coronary artery (Fig. 2c). The entire fistula filled only from the left coronary artery. The circumflex artery was normal and not dominant. The area of the fistula was faintly calcified.

\section{Discussion}

Angina as a manifestation of fistula of the coronary artery is by no means uncommon in adults (Eie and Hillestad, 1971). Fistulae rarely communicate with the left side of the heart and when they do the atrium is usually involved (Effler et al., 1967). It is rarer still for a fistula to drain from both right and left coronary systems. Okuda et al. (1973) published the sixth reported case of fistula from the right coronary artery to the left ventricle in March 1973. Reddy et al. (1974) reported on a 58-year-old man with a fistula draining all three vessels into the left ventricle. The site of the fistula in their case corresponds exactly to the patient presented here, but that patient had no evidence of previous myocardial infarction.

A coronary artery 'steal syndrome', usually associated with left-to-right shunt, can sometimes be responsible for the symptoms associated with an arteriosystemic communication. Though the steal syndrome could give rise to ischaemia and even to infarction, it is unlikely that our patient had coronary steal alone. Three possibilities exist: (a) the patient had coexistent congenital fistula and coronary disease, (b) the patient had a congenital anomaly of his distal and left coronary arteries with a fistula, or (c) the right ventricular communication evolved from infarction of the inferoapical portion of his septum with extensive collateralisation and reopening of the thebesian veins. The last of these alternatives was suggested earlier by Phillips and Libanoff (1974).

Several features of our case might favour this last explanation. The patient had many risk factors for coronary artery disease. There were no physical signs of a fistula (no murmurs and diastolic pressure was normal). The right coronary artery was sten- osed, and the collateral vessel filling the fistula was not dilated. It is possible that the fistula arose from the infarction of the inferior wall, with collaterals developing early from the left anterior descending artery and later from the right coronary artery.

There are several reports of surgical correction of single-vessel fistulae to the left ventricle (Upshaw, 1962; Sakakibara et al., 1966; Effler et al., 1967; Reddy et al., 1974). Most reports concern correction of left-to-right shunt to prevent the consequences of haemodynamic overload, bacterial endocarditis, and steal syndrome. There is no mention in the published reports of surgical correction of a lesion similar to that described in this patient. It would, indeed, be most difficult to approach, and the results of proximal ligation of either artery to the fistula would be speculative to say the least. We, therefore, elected to treat this patient medically.

\section{References}

de Nef, J. J. E., Varghese, P. J., and Losekoot, G. (1971). Congenital coronary artery fistula: analysis of 17 cases. British Heart fournal, 33, 857-862.

Effler, D. B., Sheldon, W. C., Turner, J. J., and Groves, L. K. (1967). Coronary arteriovenous fistulas: diagnosis and surgical management. Report of 15 cases. Surgery, 61, 41-50.

Eie, H., and Hillestad, L. (1971). Arterio-venous fistulae of the coronary arteries: a report of six cases. Scandanavian fournal of Thoracic and Cardiovascular Surgery, 5, 34-38.

Hallman, G. L., Cooley, D. A., and Singer, D. B. (1966). Congenital anomalies of the coronary arteries: anatomy, pathological, and surgical treatment. Surgery, 59, 133-144.

McNamara, J. J., and Gross, R. E. (1969). Congenital coronary artery fistula. Surgery, 65, 59-69.

Ogden, J. A., and Stansel, H. C., Jr. (1972). Coronary arterial fistulas terminating in the coronary venous system. Fournal of Thoracic and Cardiovascular Surgery, 63, 172-182.

Okuda, Y., Tsuneda, T., Morishima, A., Matsumoto, S., Ito, Y., and Tsuzuki (1973). Right coronary artery to left ventricle fistula; the sixth case in the literature and discussion. Fapanese Heart fournal, 14, 184-191.

Phillips, P. A., and Libanoff, A. J. (1974). Arteriovenous communication associated with obstructive arteriosclerotic coronary artery disease and myocardial infarction. Chest, 65, 106-108.

Reddy, K., Gupta, M., and Hamby, R. I. (1974). Multiple coronary arteriosystemic fistulas. American fournal of Cardiology, 33, 304-306.

Sakakibara, S., Yokoyama, M., Takao, A. Nogi, M., and Gomi, H. (1966). Coronary arteriovenous fistula: nine operated cases. American Heart fournal, 72, 307-314.

Upshaw, C. B., Jr. (1962). Congenital coronary arteriovenous fistula. Report of a case with an analysis of 73 reported cases. American Heart fournal, 63, 399-404.

Requests for reprints to Dr. Edward W. Gertz, Veterans Administration Hospital 111-C1, 4150 Clement Street, San Francisco, California 94121, U.S.A. 